\title{
Închidere percutană a unei hernii posttraumatice de perete abdominal
}

\author{
Maria Popescu, Gabriel Drăgan \\ Departamentul de Chirugie Pediatrică, Spitalul Clinic de Copii „Dr. Victor Gomoiu“, București, România
}

\begin{abstract}
REZUMAT
Herniile de perete abdominal posttraumatice sunt extrem de rare și se produc prin impactul peretelui cu un obiect ce nu străpunge tegumentul, dar are suficientă forță pentru a disocia structurile musculo-aponevrotice subiacente. Unul din cele mai frecvente mecanisme de producere în populația pediatrică este lovitura cu ghidonul de bicicletă. Vă prezentăm cazul unui pacient de sex masculin în vârstă de 13 ani diagnosticat cu hernie posttraumatică prin lovitură cu ghidonul de bicicletă la nivelul hemiabdomenului drept, prin examinare CT. Procedura chirurgicală aleasă a fost repararea peretelui abdominal folosind fire introduse prin manieră PIRS (percutaneous internal ring suturing) asistată laparoscopic. Evoluția cazului a fost fără complicații postoperatorii.
\end{abstract}

Cuvinte cheie: hernie de perete abdominal posttraumatică, ghidon de bicicletă, laparoscopie, examinare CT

\begin{abstract}
Abrevieri
TAWH - traumatic abdominal wall hernia

$\mathrm{HH}$ - handlebar hernia

PIRS - percutaneous internal ring suturing
\end{abstract}

\section{INTRODUCERE}

Herniile de perete abdominal posttraumatice sunt extrem de rare în populația pediatrică. Mecanismul de producere constă în impactul la o viteză mică a peretelui abdominal cu un obiect suficient de bont pentru a nu penetra pielea (datorită elasticității), dar suficient de puternic pentru a produce ruptura fibrelor musculare şi a fasciei aponenevrotice. Herniile prin lovitură cu ghidonul de bicicletă sunt cea mai frecventă cauză de apariție a acestei leziuni traumatice. Printre alte tipuri de mecanisme de producere a herniilor traumatice de perete abdominal, putem enumera lovituri cu coada toporului, alte tipuri de ghidoane (motocicletă, plug, roabă), lovituri ale coarnelor animalelor (tauri) sau rar, prin leziuni de decelerare (1). Incidența acestui tip de defect de perete la copii este de aproximativ $1 \%$, cu o prevalență a herniilor prin lovitură cu ghidonul de bicicletă în proporție de $85 \%$ (2).

Toate cazurile descrise în literatură de hernie prin lovitură cu ghidonul de bicicletă au fost rezolvate chirurgical, cu excepția unuia, metoda de elecție fiind aproximarea defectului cu sau fără material prostetic (3). Tehnica laparoscopică a fost în principal folosită pentru diagnostic în cazul traumatismelor la care se suspiciona leziunea concomitentă a unui organ intraabdominal sau în cazul pacienților cu examinare CT neconcludentă (4).

Vă prezentăm cazul unui băiat, în vârstă de 13 ani, care a fost diagnosticat cu hernie prin lovitură cu ghidonul de bicicletă. Am obținut consimțământul informat al părinţilor pentru includerea în articol a datelor şi imaginilor clinice și imagistice ale pacientului.

\section{PREZENTAREA CAZULUI}

\section{Motivele internării}

Prezentăm cazul unui pacient de sex masculin, în vârstă de 13 ani, internat în departamentul nostru de chirurgie la 24 de ore după un incident traumatic prin cădere de pe bicicletă și lovitură cu ghidonul în cadranul abdominal inferior drept. La internare, pacien- 
tul acuză dureri abdominale difuze, cu nivel maxim la nivelul zonei de impact, unde se constată bombarea peretelui abdominal.

\section{Aspecte clinice}

Examenul clinic confirmă prezența la nivelul fosei iliace drepte a unei formațiuni tumorale subcutanate, cu dimensiuni aproximative de $10 \times 6 \mathrm{~cm}$, dureroasă, reductibilă, cu marcă traumatică, echimoză, supraiacentă ariei de impact (Fig. 1). Formațiunea tumorală este vizibilă în clinostatism și ortostatism, expansionează la manevrele de creștere a presiunii intraabdominale și palpator se constată o mărime a defectului de aproximativ $7 \mathrm{~cm}$. Examenul clinic nu constată alte elemente patologice la internare.

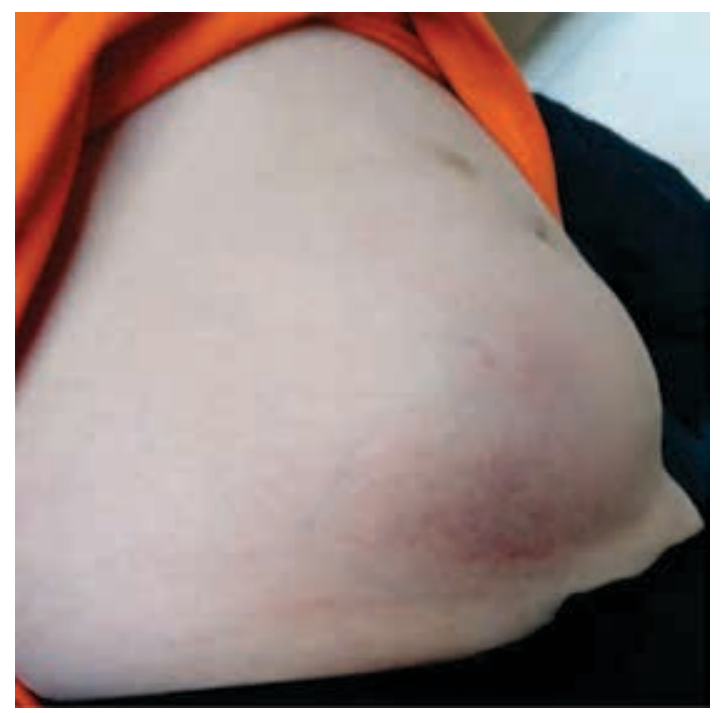

FIGURA 1. Hematom de perete abdominal şi bombarea peretelui

\section{Criterii de diagnostic şi evaluare}

Investigațiile de laborator efectuate la internare nu au prezentat modificări importante. Examinarea CT efectuată în urgență confirmă diagnosticul de hernie traumatică de perete abdominal prin ruptura straturilor musculare, oblic intern şi extern, transvers abdominal și a peritoneului, cu hernierea la nivel subcutanat a unei anse de intestin gros prin defectul aponevrotic. $\mathrm{Nu}$ s-au constatat alte leziuni ale organelor parenchimatoase sau cavitare (figurile 2 şi 3 ).

\section{Management terapeutic}

La 48 de ore de la evenimentul traumatic, s-a intervenit laparoscopic, cu constatarea rupturii tuturor straturilor peretelui abdominal și a peritoneului, ansă de colon și epiplon herniate subcutanat, unde au dezvoltat un sindrom aderențial ce s-a desfăcut cu ușurință (Fig. 4). La inspecția cavității abdominale, nu s-au constatat alte leziuni de organe. Am efectuat

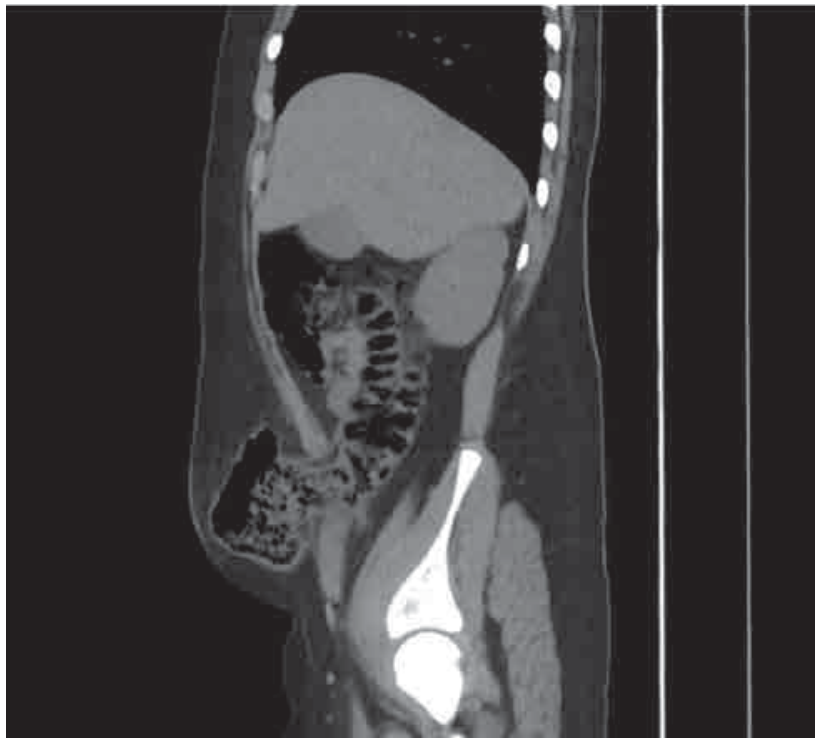

FIGURA 2. Examinare CT a herniei de perete abdominal (aspect transversal)

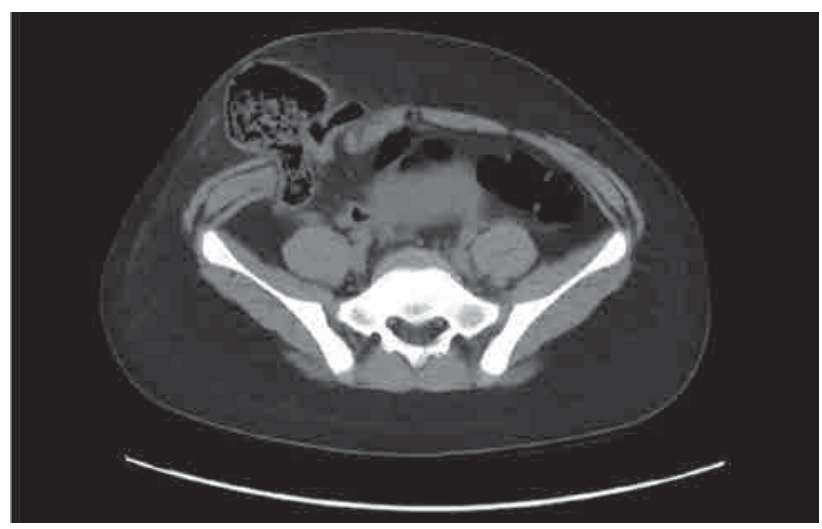

FIGURA 3. Examinare CT a herniei de perete abdominal (aspect lateral)

repararea defectului, adaptând tehnica de sutură cu noduri extracorporeale a inelului de hernie inghinal (PIRS), care ne-a permis aproximarea celor două margini ale defectului într-un singur strat cu fire neresorbabile 2-0 (Fig. 5, 6). Am introdus o lamă de dren supraaponevrotic, care a fost înlăturată la 2 zile postoperator.

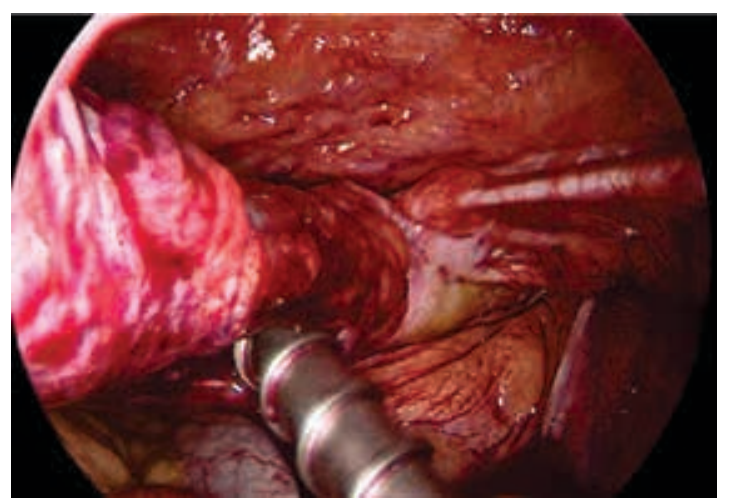

FIGURA 4. Aspect laparoscopic al celor

2 margini ale defectului 


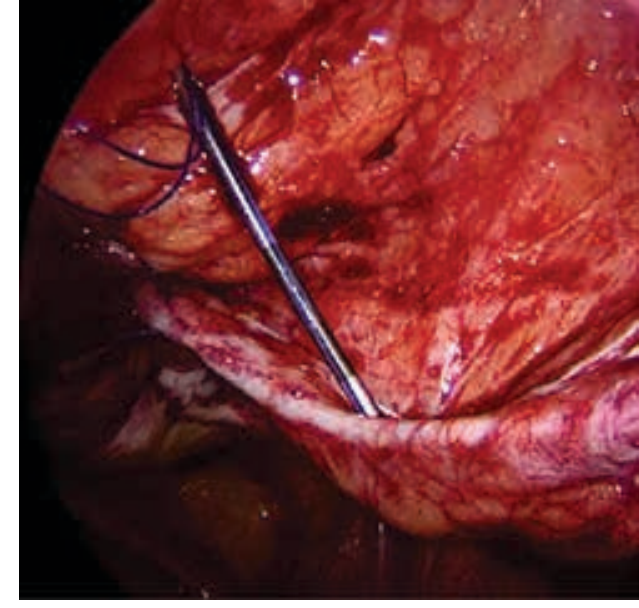

FIGURA 5. Adaptarea procedurii PIRS de sutură a defectului herniar

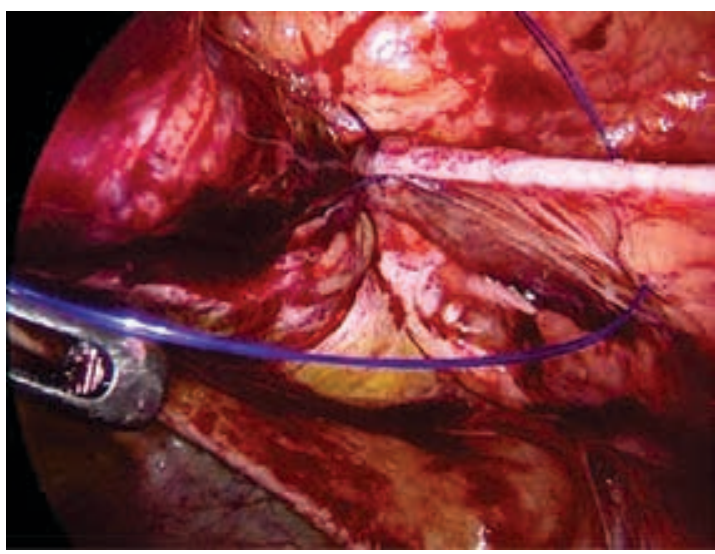

FIGURA 6. Buclă a firului de sutură intracorporeală cu nod efectuat extracorporeal pentru aproximarea celor două margini ale defectului

\section{Urmărire postoperatorie şi monitorizare}

Evoluție favorabilă fără complicații, cu externarea pacientului la patru zile după intervenția chirurgicală. Controlul postoperator la o lună și cel la 6 luni postoperator nu au evidențiat recidivă locală (Fig. 7).

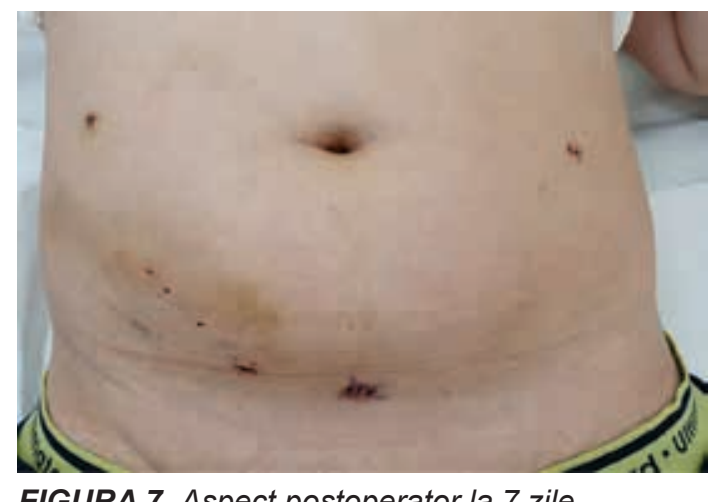

FIGURA 7. Aspect postoperator la 7 zile

\section{DISCUTุII}

Herniile posttraumatice de perete abdominal reprezintă o patologie rar întâlnită în populația pediatri- că, literatura de specialitate bazându-se pe raportări de cazuri și statistici pe un număr redus de pacienți provenind din centrele de nivel I de traumatisme (2). Atunci când se evaluează un traumatism abdominal, este foarte importantă efectuarea unui examen clinic complet, acordând o atenție deosebită celei mai afectate regiuni. În cazul pacientului nostru, localizarea zonei de hernie a fost una dintre cele mai comune pentru defectele posttraumatice de perete abdominal. Acestea se regasesc cel mai frecvent în cadranul abdominal inferior, lateral de fascia drepților abdominali, prin dehiscența mușchilor oblici, a transversului abdominal și protruzia factorului traumatic în regiunea fosei iliace. Cadranul abdominal inferior drept reprezintă cea mai frecventă localizare, dar putem găsi defecte posttraumatice și la nivelul hemiabdomenului stâng sau în porțiunile posterolaterale (2). Puține cazuri asociază hernie diafragmatică concomitentă sau defecte care implică mai mult de o regiune, factori care sugerează ca mecanism fiziopatologic creșterea presiunii intraabdominale (5).

Un factor important care influențează alegerea tehnicii chirurgicale folosite este mărimea zonei herniare. Dimensiunile defectului în cazul prezentat, măsurate intraoperator, sunt $7 / 4 \mathrm{~cm}$, probabil datorate ghidonului de bicicletă de proporţii mai mari. Conform literaturii de specialitate, herniile posttraumatice de perete abdominal se pot clasifica în 3 categorii, ținând cont de mărimea defectului și de mecanismul de producere: tipul I, cu defect de dimensiuni mici (herniile prin ghidon de bicicletă), tipul II, cu defect mai mare (accidente de motocicletă sau căderi de la înălţime), și tipul III, hernierea anselor intestinale prin orice tip de defect având ca mecanism decelerarea $(2,6)$.

Din cauza rarității acestui tip de patologie, stabilirea diagnosticului de hernie de perete abdominal posttraumatică și a posibilelor leziuni asociate este dificilă. $\mathrm{Cu}$ toate că examenul clinic al pacientului nostru nu a relevat posibile complicații locale sau sistemice, am decis efectuarea cât mai rapidă a unui CT abdominal pentru evaluarea defectului și a posibilelor complicații asociate. Acestea din urmă sunt în general prezente atunci când impactul a avut loc la nivelul abdomenului superior, dar statistica relevă o asociere a herniilor prin lovitură cu ghidonul de bicicletă în $8 \%$ dintre cazuri cu leziuni urologice, splenice, hepatice, pancreatice, ale anselor intestinale sau ale mezenterului $(2,4)$. Accesul facil la investigații radiologice, cum este CT-ul, în toate centrele de traumatisme, îl desemnează ca fiind investigația de elecţie în cazul unui traumatism de perete abdominal. $\mathrm{Cu}$ toate că examinarea $\mathrm{CT}$ are senzitivitate şi specificitate mare în detecția unui defect de perete abdo- 
minal, trebuie să insistăm asupra importanței urmăririi în evoluție a elementelor examenului clinic, a căror agravare poate impune necesitatea unei intervenții operatorii, exploratorii, chiar în absența unor semne radiologice clare. Susținem importanța examinărilor radiologice seriate și a monitorizării atente a evoluției clinice a pacientului, prin consulturi repetate, mai ales în cazurile cu un grad mare de suspiciune de leziuni intraabdominale asociate $(2,5)$.

Alegerea momentului operator pentru repararea hernie abdominale și tipul de intervenție chirurgicală folosită ar trebui să fie decise pentru fiecare caz în parte ținându-se cont de statusul hemodinamic al pacientului, evaluările clinice și $\mathrm{CT}$ seriate. Pacientul nu a prezentat episoade de decompensare hemodinamică, examinarea CT nu a relevat alte leziuni asociate intraabdominale și am decis efectuarea unei intervenţii chirurgicale laparoscopice, programată la 24 de ore de la internare și la 48 de ore de la traumatism. Pledăm pentru folosirea laparotomiei în urgență (la 24 de ore de la internare) în cazul instabilității hemodinamice a unui pacient, asociată cu un indice mare de suspiciune a unor leziuni intraabdominale în cazul unui traumatism de forță crescută, ce a dus la apariția unei hernii posttraumatice, pentru a scădea riscul de complicații ulterioare și pentru a repara defectul de perete. Pentru pacienții stabili din punct de vedere hemodinamic sau în cazul absenței unui diagnostic de certitudine, considerăm intervenția laparoscopică ca fiind indicată atât ca metodă diagnostică, cât și curativă $(5,6)$.

În cazul pacientului nostru, decizia de a folosi o variantă adaptată de PIRS (percutaneous internal ring

Conflict of interest: none declared

Financial support: none declared

\section{BIBLIOGRAFIE}

1. Kubota A, Shono J, Yonekura T, Hoki M, Asano S, Hirooka S, Kosumi T, Kato M, Oyanagi H. Handlebar hernia: case report and review of pediatric cases. Pediatr Surg Int. 1999 Jul;15(5-6):411-2.

2. Hafezi N, Raymond JL, Mayo ED, Rouse TM, Billmire DF, Gray BW. Traumatic abdominal wall hernias in children: A case for early exploration. J Pediatr Surg. 2020 Jul 12:S0022-3468(20)30480-2.

3. Litton K, Izzidien AY, Hussien O, Vali A. Conservative management of a traumatic abdominal wall hernia after a bicycle handlebar injury (case report and literature review). J Pediatr Surg. 2008 Apr;43(4):e31-2.

4. linuma Y, Yamazaki $Y$, Hirose $Y$, Kinoshita H, Kumagai K, Tanaka T, Miyajima M, Nitta K, Naitoh S, Kobayashi K. A case of a traumatic suture) asistată laparoscopic a fost ca urmare a distanței de peste $4 \mathrm{~cm}$ între cele două margini ale defectului și scăderea riscului de dehiscență a suturilor datorită efectuării nodurilor la vedere, extracorporeal, folosind fire de sutură neabsorbabile. Pentru a evita apariţia unor complicații severe, ocluzie intestinală prin încarcerarea sau strangularea herniei intraabdominale, se recomandă repararea defectului de perete abdominal cu fire neabsorbabile fără o tensiune importantă în momentul aproximării marginilor defectului, precum şi explorarea atentă a întregii cavității peritoneale. Folosirea de materiale prostetice este foarte rară în cazul cazuisticii pediatrice și este rezervată numai pentru defectele de perete abdominal de dimensiuni crescute, pentru care este imposibilă aproximarea celor două margini fără să fie în tensiune $(1,5)$.

Tratamentul conservator al herniei posttraumatice de perete abdominal este descris în literatură pentru un caz și s-a datorat unor dimensiuni mici ale defectului și absenței asocierii unor leziuni concomitente ale organelor intraabdominale (3).

\section{CONCLUZII}

Când ne aflăm în fața unui pacient cu suspiciune de hernie posttraumatică de perete abdominal, stabilirea planului de investigații și terapeutic trebuie sa fie adaptată individual pentru fiecare caz, ţinând cont de o anamneză amănunțită, examen clinic și CT, iar momentul operator și tipul de tehnică chirurgicală aleasă reflectă importanța factorului decizional din partea chirurgului. abdominal wall hernia that could not be identified until exploratory laparoscopy was performed. Pediatr Surg Int. 2005 Jan;21(1):54-7.

5. Talutis SD, Muensterer OJ, Pandya S, McBride W, Stringel G. Laparoscopic-assisted management of traumatic abdominal wall hernias in children: case series and a review of the literature. J Pediatr Surg. 2015 Mar;50(3):456-61.

6. Chen HY, Sheu MH, Tseng LM. Bicycle-handlebar hernia: a rare traumatic abdominal wall hernia. J Chin Med Assoc. 2005 Jun;68(6):283-5. 